\author{
Research Article \\ www.ijrap.net
}

\title{
EVALUATION OF MAJOR PHYTOCHEMICALS IN THE LEAVES AND FRUITS OF SOLANUM MAURITIANUM SCOP.: A POTENTIAL HERBAL DRUG
}

\author{
$\mathrm{K}$ Jayakumar ${ }^{1}$ and $\mathrm{K}$ Murugan ${ }^{2 *}$
}

${ }^{1}$ Department of Botany, SVR NSS College, Kottayam, India

${ }_{2}^{2}$ Plant Biochemistry and Molecular Biology Lab, Department of Botany, University College, Trivandrum, Kerala, India

Received on: 02/11/15 Revised on: 14/12/15 Accepted on: 12/01/16

*Corresponding author
E-mail: harimurukan@gmail.com

DOI: $10.7897 / 2277-4343.07257$

\section{ABSTRACT}

Phytochemicals isolation and identification is utmost important to know the active principles of medicinal plants. Solanum L., is used in folk and traditional medicine to cure many disorders. Bug weed (Solanum mauritianum Scop.) is evergreen woody shrub of South America. Local people use this exotic species for curing many ailments. A preliminary evaluation was attempted to know the major phytochemicals in this species to validate its usage. The leaves and fruits were screened for quantification of major phytochemicals such as alkaloids, flavonoids, saponins, tannins and phenolic compounds. Significant levels of alkaloid $(0.59-0.34 \mathrm{mg} / \mathrm{g})$, saponin $(4.3-6.4 \mathrm{mg} / \mathrm{g})$, phenolic content $(7.2-11.7 \mathrm{mg} / \mathrm{g})$, tannin $(4.59-7.4 \mathrm{mg} / \mathrm{g}) \mathrm{has}$ been detected in the leaves and fruits of this plant. It is fascinating to note that the polyphenols and alkaloids displayed remarkable levels. Thus, the present study reveals medicinal potentiality of the plant. These phytochemicals possess various bioactive properties and may be used as external therapeutic supplement. Further studies are warranted to isolate, fractionate the alkaloids from the leaves and to elucidate its structure.

Key words: Solanum, quantitative estimation, therapeutic value, alkaloid, polyphenols.

\section{INTRODUCTION}

Plant-based secondary metabolites are potential as defense molecules or as agents of pollination. Secondary metabolites are generally utilized in food, pharmaceutical, chemical, cosmetic industries and also in agriculture. Herbal natural products are abundant in nature and many of them exhibit unique biological activities and some can be used as food additives. Synthetic antioxidants used in the food industry show many health-related issues and most developed countries are tending to give preferences to natural sources. Therefore, investigation of natural molecules has been a changing trend in pharmaceutical research. Antioxidants mitigate oxidative deterioration of food and indirectly scavenging free radicals from it. Butylated hydroxyanisole, butylated hydroxytoluene, propyl gallate and tertiary butylhydroquinone are synthetic antioxidants used in foods to prevent oxidative degradation. No single phytocomponent is responsible for its medicinal properties of many plant-based drugs, and usually their synergic action enhances its efficacy. Therefore, the determination of the total amount of diverse groups of components is essential for the standardization of the plants. Polyphenols, saponins and alkaloids are proven phytochemicals in many plants and display with characteristic toxicity and pharmacological activity. These features are traditionally being exploited by humans for hunting gathering stage in executing drugs.

The genus Solanum L., belongs to Solanaceae and is considered as one of the largest genus among the angiosperms with great potential for food security in the developing world. It comprises of about 1500 species and well represented all over the globe. It is rich in alkaloids which are distributed in all parts of the plants. The active principles such as solinidine and other steroids extracted from the roots and leaves of some species are of potent and effective pharmaceuticals. Majority of the Solanum species are widely used in folk medicine. The presence of the steroidal alkaloid solasodine, a precursor for the synthesis of steroid hormones and is characteristic active principle of Solanum species. This has tremendous impact on utilization of this genus economically and medicinally all over the world. The lack of immediate known use for certain members of this group has lead to their neglect and subsequent genetic erosion. Depletion of such potentially useful plant resources should be taken care of by paying attention to germ plasm exploration and conservation studies. The present study was focused on phytochemical analysis of Solanum mauritianum Scop. used locally in traditional and folk medicine to cure many disorders.

\section{MATERIALS AND METHODS}

\section{Plant material}

Fresh leaves and ripened fruits of Solanum mauritianum Scop. were collected from Munnar hills of Idukki district, Kerala. The plant was identified, authenticated by referring manuals and confirmed by referring the herbarium of Jawaharlal Nehru Tropical Botanical Garden and Research Institute (JNTBGRI). The herbarium specimen was deposited in the herbarium of University College, Trivandrum (UCT 1279). The plant was collected during September- October.

\section{Experimental}

The samples were shade dried and made in to fine powder for quantitative analysis.

\section{Quantification of total alkaloids}

\section{Alkaloids estimation}

Crude alkaloid content was estimated using Dragendorff's reagent following the protocol of Luis et al., 2012 ${ }^{1}$ Briefly, 10 $\mathrm{ml}$ of each crude ethanolic extract was centrifuged over $10 \mathrm{~min}$ $(3000 \mathrm{rpm})$ to remove residual suspended particles. $5 \mathrm{ml}$ of the supernatant were mixed with $1 \mathrm{ml}$ of $0.1 \mathrm{~N} \mathrm{HCl}$. Add $2.5 \mathrm{ml}$ of 
Dragendorff's reagent to the previous mixture for precipitation and the precipitate was centrifuged for $5 \mathrm{~min}$ (3000 rpm). Subsequently, the precipitate was washed with $2.5 \mathrm{ml}$ ethanol. Discard the filtrate and the pellet was treated with $2.5 \mathrm{ml}$ of disodium sulfide solution $(1 \% \mathrm{w} / \mathrm{v})$. The resulted brownish black precipitate was then centrifuged for $5 \mathrm{~min}(3000 \mathrm{rpm})$. This residue was redissolved in $2 \mathrm{ml}$ of conc. nitric acid, with slight warming. This solution was diluted with distilled water to $10 \mathrm{ml}$ in a standard flask. Then, pipette out $1 \mathrm{ml}$ and mixed with $5 \mathrm{ml}$ of thiourea solution $(3 \% \mathrm{w} / \mathrm{v})$. Absorbance of this solution was read at $435 \mathrm{~nm}$ against blank containing $1 \mathrm{ml}$ of conc. nitric acid $+2.5 \mathrm{ml}$ of thiourea solution $(3 \% \mathrm{w} / \mathrm{v})$. The standard curve was prepared using pilocarpine nitrate $(750,500,400,250,200$, 150 and $100 \mathrm{mg} / \mathrm{ml}$ solutions) in $\mathrm{HCl} 0.1 \mathrm{~N}(\mathrm{y}=0.0012 \mathrm{x}-$ $0.1044 ; \mathrm{R} 2=0.9851)$. Total crude alkaloid contents were expressed as pilocarpine nitrate equivalents $(\mathrm{mg} \mathrm{PNE} / \mathrm{g}$ of dry mass).

\section{Estimation of total flavonoids}

Total flavonoid level of leaves and fruits was determined using the aluminium chloride method. $0.5 \mathrm{ml}$ of extracts was taken in different test tubes and adds $2 \mathrm{ml}$ of distilled water $+0.15 \mathrm{ml}$ of sodium nitrite $(5 \% \mathrm{w} / \mathrm{v})$ and allowed to stand for $6 \mathrm{~min}$. Later, add aluminium trichloride $(10 \%, 0.15 \mathrm{ml})$ and incubate for 6 $\mathrm{min}$, followed by the addition of $2 \mathrm{ml}$ of sodium hydroxide $(4 \%$ $\mathrm{w} / \mathrm{v})$. The volume was made up to $5 \mathrm{ml}$ with distilled water. After 15 min of incubation the reaction mixture turns into pink and read the absorbance at $510 \mathrm{~nm}$. Distilled water was used as blank. Flavonoid level was expressed in $\mathrm{mg}$ of catechin equivalents (CE) per $g$ of extract ${ }^{2}$.

\section{Determination of total Phenols}

$100 \mathrm{mg}$ of the sample was extracted with $5 \mathrm{ml}$ of $80 \%$ ethanol and centrifuged at $2000 \mathrm{rpm}$. $1 \mathrm{ml}$ of folin-ciocalteu reagent was added to $0.5 \mathrm{ml}$ of the extract of the sample. $2 \mathrm{ml}$ of $20 \%$ sodium carbonate was added and heated for $1 \mathrm{~min}$. After cooling, the solution was made up to $10 \mathrm{ml}$ with distilled water. The blank contains all the reagents except the sample. The OD was read at $650 \mathrm{~nm}$ wavelength ${ }^{3}$.

\section{Estimation of saponin}

$10 \mathrm{~g}$ of powdered leaf and fruit samples in $100 \mathrm{ml}$ of dilute ethanol (20\%) were taken in two different $250 \mathrm{ml}$ conical flask. The ethanolic mixture was heated at $60^{\circ} \mathrm{C}$ for $6 \mathrm{~h}$ with gentle stirring in a hot water bath. Subsequently, the residue was filtrated by a Whatman filter paper No. 1. The filtrate was kept in new container. Further, the pellet was subjected to the same protocol for elucidating the maximum yield. The resulted fractions were mixed and heated till the volume of the residue was reduced to $20-25 \%$. The concentrated crude compound was shaken with $20 \mathrm{ml}$ of diethyl ether in a separating funnel. Separate the aqueous layer and the process was repeated twice. Lastly, mix the residue with n-butanol and washed thrice with $10 \mathrm{ml} 5 \% \mathrm{NaCl}$ solution. The semisolid was dried in an oven and the saponin level was estimated ${ }^{4}$.

\section{Determination of Tannins}

$500 \mathrm{mg}$ powdered sample was transferred to $250 \mathrm{ml}$ conical flask containing $75 \mathrm{ml}$ of distilled water and boiled for $30 \mathrm{~min}$. The residue was centrifuged for $2000 \mathrm{rpm}$ for $20 \mathrm{~min}$. The supernatant was collected in $100 \mathrm{ml}$ volumetric flask and made up to a known volume. $1 \mathrm{ml}$ of the sample extract was transferred to a $100 \mathrm{ml}$ volumetric flask containing $75 \mathrm{ml}$ of distilled water. To this, add $5 \mathrm{ml}$ of Folin-Denis reagent and 10 $\mathrm{ml}$ of sodium carbonate solution and diluted to $100 \mathrm{ml}$. It was shaken thoroughly and left for $30 \mathrm{~min}$. The absorbance was read at $700 \mathrm{~nm}$ against blank as water ${ }^{5}$.

\section{Statistical analysis}

The results were recorded after repeating the experiments six times. The experimental results were expressed as mean \pm standard deviation of (6n) measurements. The statistical analysis of the data was carried out using student's t-test and the results were considered significant when $p<0.05$.

\section{RESULTS AND DISCUSSION}

Therapeutic use of herbals dates back to the $\mathrm{BC}$ and is still utilized to cure many ailments in most part of the world. Developed countries referred this as Complementary and Alternative Medicine. Most of the local ethnic societies inhabitated in the village prone areas depends basically on plant based crude extracts. The efficacy of these extracts is based on the pool of secondary metabolites which act synergistically to cure the disease. Different plant parts contain varying amounts of phytochemicals such as roots, leaves, fruits or seeds. The principle molecule often may cause toxicity in the cells. In this juncture phytochemicals in $S$. mauritianum was analyzed to validate its use as drug by the local people. Leaves and mature fruits were analyzed.

The fruits of $S$. mauritianum contained high level of flavonoids $(5.6 \mathrm{mg} / \mathrm{g})$ followed by leaves $(4.2 \mathrm{mg} / \mathrm{g})$. Meanwhile, the saponin content was high in the leaves $(6.4 \mathrm{mg} / \mathrm{g})$ followed by the leaves $(4.3 \mathrm{mg} / \mathrm{g})$. Total phenol content was registered high in the leaves $(11.7 \mathrm{mg} / \mathrm{g})$ followed by fruits $(7.2 \mathrm{mg} / \mathrm{g})$. Remarkable percentage of alkaloid has been detected in the leaves of the species $(0.59 \mathrm{~g} \pm 0.08)$ compared to fruits $(0.34 \mathrm{~g} \pm$ 0.04). Tannin also showed optimal level i.e., 4.89 to $7.4 \mathrm{mg} / \mathrm{g}$ in the leaves and fruits (Table 1).

Alkaloids are class of nitrogen containing natural compound. Diverse 12,000 alkaloids are reported in about $20 \%$ of plant species and limited of them are exploited commercially as medicinal such as vinblastine and vincristine (anti-tumor agents), reserpine (anti-hypertensive) and quinine (anti-malarial agent). The bioactive phytochemicals of $S$. mauritianum may play vital role in developing anti-tumor drugs in human being.

Saponins are high molecular weight compound. Sugar molecule present in the saponin combined with triterpene or steroid glycone to form glycosides which has cholesterol binding property. Similarly, it displays antimicrobial properties ${ }^{6,7}$. Therapeutically, they are shown to have hypo lipidemic and anti-cancer activity i.e., they react with cholesterol rich plasma membrane of various cancer cells and inhibits their proliferation $^{8}$. High level of saponin was seen in the leaves of $S$. mauritianum.

Flavonoids are established botanicals with proven records in protecting cells against free radicals and reactive oxygen species, the products of stress in living cells. This may indirectly a boon to many degenerative diseases including myo-cardiac attack and cancer'. Further, by inhibiting the estrogen producing enzyme flavonoid blocks the cancer proliferation. The range of total flavonoid in the leaves and fruits were 4.2-5.6 $\mathrm{mg} / \mathrm{g}$.

Remarkable amount of total phenolic compound further supports its natural antioxidant potentiality and may be used as nutraceuticals. Polyphenols has ability to combat cancer, prevent heart ailments and inflammation. They are also potent vasodilator ${ }^{10}$. Gnana Sundari et al., evaluated phytochemicals in three Solanum species $S$. torvum, S.trilobatum and $S$. xanthocarpum $^{11}$. The present data is comparable with the above species. 
Table 1: Phytochemicals in the leaf and fruits of $S$. mauritianum Significance $5 \%$ level $(P<0.05)$

\begin{tabular}{|c|c|c|}
\hline Phytochemicals & Leaves & Fruits \\
\hline Saponins & $2.1 \pm 0.04$ & $1.6 \pm 0.05$ \\
\hline Alkaloids & $4.78 \pm 0.01$ & $3.5 \pm 0.12$ \\
\hline Phenols & $3.3 \pm 0.09$ & $2.7 \pm 0.04$ \\
\hline Flavonoids & $3.5 \pm 0.09$ & $2.6 \pm 0.04$ \\
\hline Tannins & $1.56 \pm 0.01$ & $1.9 \pm 0.03$ \\
\hline
\end{tabular}

Quantitative phytochemical evaluation of the seed, leaves, stem and berries of $S$. surattense, S. trilobatum and S. sisymbriifolium by Shahiladevi et al., also substantiate the present results ${ }^{12}$. Muthumani et al., estimated the total alkaloid from Solanum leave with its medicinal potentiality and were lower than that of S. mauritianum $^{13}$.

Pharmacognostical and phytochemical comparison of roots of Solanum species used in Ayurvedic formulations was chiefly based on alkaloid content. In this scenario, the high alkaloid content in $S$. mauritianum demands its further evaluation ${ }^{13}$. Major alkaloids in Solanum species are steroidal glycoalkaloids. These contain three portions: a non-polar steroid and a basic portion with either a indolizidine or oxa-azaspirodecane structure which form the aglycone part and a polar, watersoluble sugar moiety with three or four monosaccharides attached to the 3-OH group of the first ring of the aglycone. Medicinal uses of glycoalkaloids have fascinated the pharmacological industries. Solamargine and solasodine exhibit potent cytotoxicity to human hepatoma cells via apoptosis. Solasodine, solamargine, and solasonine from $S$. incanum were proven liver protective agents against $\mathrm{CCl}_{4}$-induced liver damage. Furthermore, $\alpha$-chaconine, $\alpha$-solanine, $\alpha$-solamargine, $\alpha$-solasonine, $\alpha$-tomatine and their hydrolytic products inhibit the growth of colon and liver carcinoma cells. Plasma lowdensity lipoprotein cholesterol and triglycerides was lowered by $\alpha$ - tomatine by inducing cytokines in immunized animals. Solanine and chaconine separately or jointly reduce cervical liver, lymphoma and stomach cancer ${ }^{14,15}$.

\section{CONCLUSION}

The results of the present investigation report the phytochemical analysis of phenolics, flavonoids, saponins, tannins and alkaloids present in leaves and fruits of $S$. mauritianum. However further investigations are required to isolate and characterize the active constituents from this plant to evaluate their therapeutic potential. Future studies are warranted to isolate, purify the lead molecules and evaluation of its biological potentialities.

\section{REFERENCES}

1. Luis A, Gil N, Amaral ME, Duarte AP. Antioxidant Activities of Extracts from Acacia Melanoxylon, Acacia dealbata and Olea europaea and Alkaloids Estimation. Int J Pharm Pharm Sci 2012; 4(1):225-231.

2. Pourmorad F, Hosseinimeh S, Shahabimajd N. Antioxidant Activity, Phenol and Flavonoid Contents of Some Selected Iranian Medicinal Plants. African J Biotechnol 2006; 5(11):1142-1145.

3. Tawaha K, Alali F, Gharaibeh M, Mohammad M, El-Elimat M, Mohammad M, El-Elimat T. Antioxidant Activity and
Total Phenolic Content of Selected Jordanian Species. Food Chem 2007; 104:1372-1378.

4. Somit D, Priyankar D, Kumar CT. Quantification and Correlation of the Bioactive Phytochemicals of Croton bonplandianum Leaves of Sub-Himalayan Region of West Bengal. Asian J Pharm Clin Res 2013; 6(3):142-147.

5. Neelima N, Gajanan Devidas N, Sudhakar M, Jadhav Kiran VA. Preliminary Phytochemical Investigation on the Leaves of Solanum xanthocarpum. Int J Res Ayurveda Pharm 2011; 2(3):845-850.

6. Asl MN, Hosseinzadeh H. Review of Pharmacological Effects of Glycyrrhiza sp. and its Bioactive Compounds. Phytother Res 2008; 22(6):709-24.

7. Xu R, Zhao W, Xu J, Shao B, Qin G. Studies on Bioactive Saponins from Chinese Medicinal Plants. Adv Exp Med Biol 1996; 404:371-82.

8. Rao AV, Sung MK. Saponins as Anticarcinogens. J Nutrition 1995; 125(3):717-724.

9. Kar A. Pharmaocgnosy and Pharmacobiotechnology. Revised-expanded $2^{\text {nd }}$ ed. New Delhi: New Age International Limited Publishers; 2007. p. 332-600

10. Padilla E, Ruiz E, Redondo S, Gordillo-Moscoso A, Slowing K, Tejerina T. Relationship Between Vasodilation Capacity and Phenolic Content of Spanish Wines. Eur J Pharmacol 2005; 517(1-2):84-91.

11. S. Gnana Sundari, S. Rekha and A. Parvathi. Phytochemical evaluation of three species of Solanum L. Int. J. Res. Ayurveda Pharm. 2013;4(3):420-425 DOI: 10.7897/22774343.04323

12. Shahiladevi S, Jayanthi G, Jegadeesan M. Preliminary Phytochemical Studies on Solanum surattense Burm.F. Seeds. Anc Sci Life 2006; 26:59-64.

13. Muthumani P, Meera R, Sweetlin, Devi P. Phyto Chemical Investigation and Determination of Crude Alkaloidal Content (Solasodine) in Solanum leave Dunal (Dry and Fresh Berries). Intern J Pharma \& Bio Archives 2010; 1(4):350-354.

14. Jayanthy A, Sulaiman CT, Rema Shree AB. Pharmacognostical and Phytochemical Comparison of Roots of Solanum Species Used in Ayurvedic Formulations. Int. J. Pharmacognosy and Phytochem. Res 2012; 4(1):28-37.

15. Bhattacharya S, Kohli S, Chaudhary AS. Isolation of Solasodine from the Unripe Fruits of Solanum xanthocarpum Schrad and Wendl. (Solanaceae) and its Anti Cancer Activity against HeLa and U937 Cell Lines. AustrlAsian J Cancer 2013; 12(3):199-213.

\section{Cite this article as:}

$\mathrm{K}$ Jayakumar and $\mathrm{K}$ Murugan. Evaluation of major phytochemicals in the leaves and fruits of Solanum mauritianum Scop.: A potential herbal drug. Int. J. Res. Ayurveda Pharm. Mar - Apr 2016;7(2):58-60 http://dx.doi.org/10.7897/22774343.07257

Disclaimer: IJRAP is solely owned by Moksha Publishing House - A non-profit publishing house, dedicated to publish quality research, while every effort has been taken to verify the accuracy of the content published in our Journal. IJRAP cannot accept any responsibility or liability for the site content and articles published. The views expressed in articles by our contributing authors are not necessarily those of IJRAP editor or editorial board members. 